\title{
A VARIAÇÃO DA TEMPERATURA E O USO DO SOLO NO BAIRRO VILA PILOTO, TRÊ LAGOAS/MS.
}

\author{
Gustavo Galvão Ferreira ${ }^{1}$
}

Andressa Gouveia Ponso ${ }^{2}$

Arnaldo Yoso Sakamoto ${ }^{3}$

\begin{abstract}
RESUMO
Estudar o clima em um nível de maior detalhe é buscar compreender a interação entre as áreas urbanizadas e o microclima de um determinado local. O objetivo da pesquisa foi de contribuir no conhecimento do microclima na cidade de Três Lagoas (MS); buscar compreender a relação entre os diferentes usos do solo e como isso pode influenciar no microclima local; avaliar a importância da arborização para o conforto térmico. $\mathrm{O}$ trabalho está fundamentado na proposta teórico metodológica para a análise do Sistema Clima Urbano (SCU). Foram realizados levantamentos bibliográficos sobre assunto; foi eleaborado o mapeamento do uso e ocupação; foram realizadas medidas de campo em diferentes pontos conforme o uso e ocupação do solo. Para as medidas serão utilizados sensores de temperatura, instalados em mini-abrigos meteorológicos. Para a identificação do tipo de tempo, serão utilizadas imagens de satélite meteorológico GOES 13 e cartas sinóticas do site do CPTEC/INPE; cartas sinóticas das $00 Z$ e $12 Z$ no site do Centro de Hidrografia da Marinha do Brasil.
\end{abstract}

PALAVRAS-CHAVE: Microclima. Arborização. Conforto Térmico.

\section{VARIATION OF TEMPERATURE AND SOIL USING THE NEIGHBORHOOD VILA PILOTO, TRÊ LAGOAS/MS.}

\footnotetext{
${ }^{1}$ Mestrando, UFMS. gustavo.galvao04@gmail.com

2 Profa. Mestre, UFMS. andressagponso@gmail.com

${ }^{3}$ Prof. Doutor, UFMS. arnaldosakamoto@gmail.com
} 


\begin{abstract}
Studying the climate in a higher level of detail is to understand the interaction between urban areas and the microclimate of a particular location. The research objective was to contribute knowledge of the microclimate in the city of Três Lagoas (MS); seek to understand the relationship between different land uses and how this can influence the local microclimate; evaluate the importance of afforestation for thermal comfort. The work is based on theoretical and methodological proposal for the analysis of urban climate system (SCU). Literature surveys have been conducted on the subject; mapping the use and occupation was prepared; Field measurements were made at different points according to the use and occupation of land. For the measurements of temperature sensors installed in mini weather shelters will be used. To identify the type of time, images of GOES 13 weather satellite and synoptic charts CPTEC / INPE site will be used; synoptic charts from $00 Z$ and $12 Z$ on the Hydrographic Center of the Brasil Navy website.
\end{abstract}

KEY-WORDS: Microclimate. Afforestation. Thermal Comfort.

\title{
VARIACIÓN DE LA TEMPERATURA Y EL USO DE LA TIERRA EN EL BARRIO VILA PILOTO, TRÊ LAGOAS/MS.
}

\section{RESUMEN}

Estudiar el clima en un nivel más detalle es tratar de entender la interacción entre las zonas urbanas y el microclima de un lugar determinado. El objetivo era aportar conocimiento del microclima en la ciudad de Três Lagoas (MS); tratar de entender la relación entre los diferentes usos de la tierra y cómo esto puede influir en el microclima local; valorar la importancia de la forestación para el confort térmico. El trabajo se basa en la propuesta metodológica teórico para el análisis del sistema de clima urbano (UCS). Se llevaron a cabo encuestas de literatura sobre el tema; eleaborado fue el mapeo del uso y la ocupación; Las mediciones de campo se realizaron en diferentes puntos de acuerdo con el uso y ocupación del suelo. Para las medidas se utilizarán sensores de temperatura, instalado en minirefugios meteorológicos. Para identificar el tipo de tiempo, se utilizaron imágenes de satélite meteorológico del GOES 13 y sinópticos mapas del sitio CPTEC / INPE; cuadros sinópticos del $00 Z$ y $12 Z$ en el sitio del Centro Hidrográfico de la Marina de Brasil.

PALABRAS-CLAVE: microclima. Forestación. Confort térmico.

\section{INTRODUÇÃO}

Segundo Pazera (1976) de todos os fenômenos relacionados ao clima urbano, os mais significativos são, sem dúvida, os que se referem às variações da temperatura. Os elementos do ambiente urbano atuam gerando esse fenômeno: 
retenção de calor pelos materiais de construção, impermeabilização do solo, verticalização das edificações, poluição, entre outros; trata-se, provavelmente, de uma das consequências climáticas mais representativas do desenvolvimento urbano.

Estudar o clima urbano é uma tarefa que necessita de uma investigação das relações entre o homem e o meio onde vive, devido às constantes modificações no ambiente natural causadas pela ação humana, com intensas atividades econômicas e sociais, causando assim modificações no clima local.

Segundo Mendonça (2003) o clima é parte fundamental no ambiente urbano e seu estudo tem fornecido importantes contribuições à questão ambiental das cidades. As condições climáticas das cidades são provenientes das modificações na paisagem natural causada pelo crescimento urbano.

Com o crescimento desordenado das cidades a falta de planejamento adequado juntamente com o aumento de fluxo de pessoas e veículos tendo como consequência um aumento na liberação de poluentes na atmosfera dessas áreas urbanas, ocasionando mudanças na estrutura climática local, afetando a qualidade de vida da população, causando modificações na relação com o ambiente natural e assim deixando a questão sobre a arborização das cidades em segundo plano.

Grande parte dos trabalhos de clima urbano principalmente os que estão dentro da escala do microclima são os de poluição e qualidade do ar, as ilhas de calor, conforto e desconforto térmico dentre outros temas.

Ilha de calor, segundo Lowry (apud PAZERA, 1976) é a existência de temperaturas mais elevadas nas áreas urbanas do que no meio rural adjacente. Os elementos do ambiente urbano atuam gerando esse fenômeno: retenção de calor pelos materiais de construção, impermeabilização do solo, verticalização das edificações, poluição, entre outros. Trata-se, provavelmente, de uma das consequências climáticas mais representativas do desenvolvimento urbano.

As ilhas de calor representam o aumento da temperatura do ar que se desenvolve das áreas mesmo ocupadas em direção às áreas mais densamente ocupadas e edificadas, é a capacidade térmica e a condutividade da superfície de absorver e liberar radiação solar durante o dia. 
Esse tipo de fenômeno climático é mais perceptível durante o período noturno devido não haver mais interferência da radiação solar, existindo somente a energia liberada pela superfície terrestre em um processo lento aumentando a temperatura do ar; há também a soma do calor pela queima de combustíveis; secura da superfície urbana; diminuição no fluxo dos ventos; intensificação do efeito estufa da camada de poluição sobre as cidades e o consumo de energia aumentam expressivamente os efeitos das ilhas de calor urbanas.

Os objetivos gerais desta pesquisa foram de contribuir no conhecimento do microclima na cidade de Três Lagoas (MS) e estudar as influências da ocupação urbana no campo térmico local.

Os objetivos específicos foram: (1) Analisar a temperatura do ar na Vila Piloto; (2) Buscar compreender a relação entre os diferentes usos do solo suas atividades cotidianas e mostrar como isso pode influenciar no microclima local; (3) Analisar e interpretar os tipos de tempos durante os períodos e suas interações com a superfície.

\section{DESENVOLVIMENTO}

\section{Metodologia Aplicada}

A presente pesquisa fundamentou-se na proposta teórico metodológica de Monteiro (1976) para a análise do Sistema Clima Urbano (SCU); tendo-se organizado a investigação (etapas) de acordo com os princípios relacionados à entrada de energia e sua transformação pelos ambientes urbanos propostos pelo autor para o Sub-Sistema Termodinâmico.

Para esta presente pesquisa foram realizados levantamentos bibliográficos sobre $o$ assunto e que contribuísse de forma significativa para construção desse trabalho.

O mapa de uso do solo da área de estudo, foi utilizado software Spring 5.1 que através de um banco de dados computadorizado as imagens foram classificadas de acordo com o tipo de uso do solo. 
Para elaboração do mapa foi usado imagem de satélite para o mapeamento do uso do solo atual do bairro a imagem do satélite CBERS 2B, do sensor HRC (High Resolution Camera), de alta resolução $(2,7 \mathrm{~m} \times 2,7 \mathrm{~m})$, na banda pancromática. $\quad A$ Órbita/Ponto da cena orbital é 160/123, com passagem no dia 25 de novembro de 2008, disponibilizada para download gratuito no site da Divisão de Geração de Imagens (DGI), do Instituto Nacional de Pesquisas Espaciais (INPE).

Após a elaboração dos mapas de uso do solo foram estabelecidos os locais dos pontos de medidas de temperaturas no bairro Vila Piloto (Figura 1), os pontos foram escolhidos de acordo com o tipo de uso do solo, quantidade de arborização e as atividades econômicas e sociais realizadas no local.

Ponto 1: localizados dentro de uma área de mata densa com presença de vegetação de médio e grande porte, esta área é denominada Área de Preservação Ambiental (APA-Júpia). Neste local também está instalado o Batalhão da Policia Militar Ambiental de Três Lagoas/MS, onde funcionam diversos projetos sociais voltados para comunidade local visando à preservação ambiental.

Ponto 2: esta localizado em uma áreas de ocupação esparsa, com presença de arborização, onde são realizadas atividades sócias diárias voltadas para comunidade como cursos de formação profissional e atividades esportivas, tendo assim uma circulação de pessoas e veículos dentro recinto.

Ponto 3: uma área de ocupação densa dentro do bairro, sem presença de arborização, ruas estreitas com pouca ventilação onde casas são bem próximas umas das outras. Essa área é predominante residencial onde as ruas são asfaltadas tendo assim grande circulação de pessoas e veículos.

Ponto 4: Inserido dentro de uma área de grande atividade industrial e de ocupação esparsa e sem presença de arborização no local, este ponto está dentro de uma cerâmica onde a veículos de grande porte e pessoas circulando pelo local. 
Figura 1: Localização dos pontos de medidas no Bairro Vila Piloto.

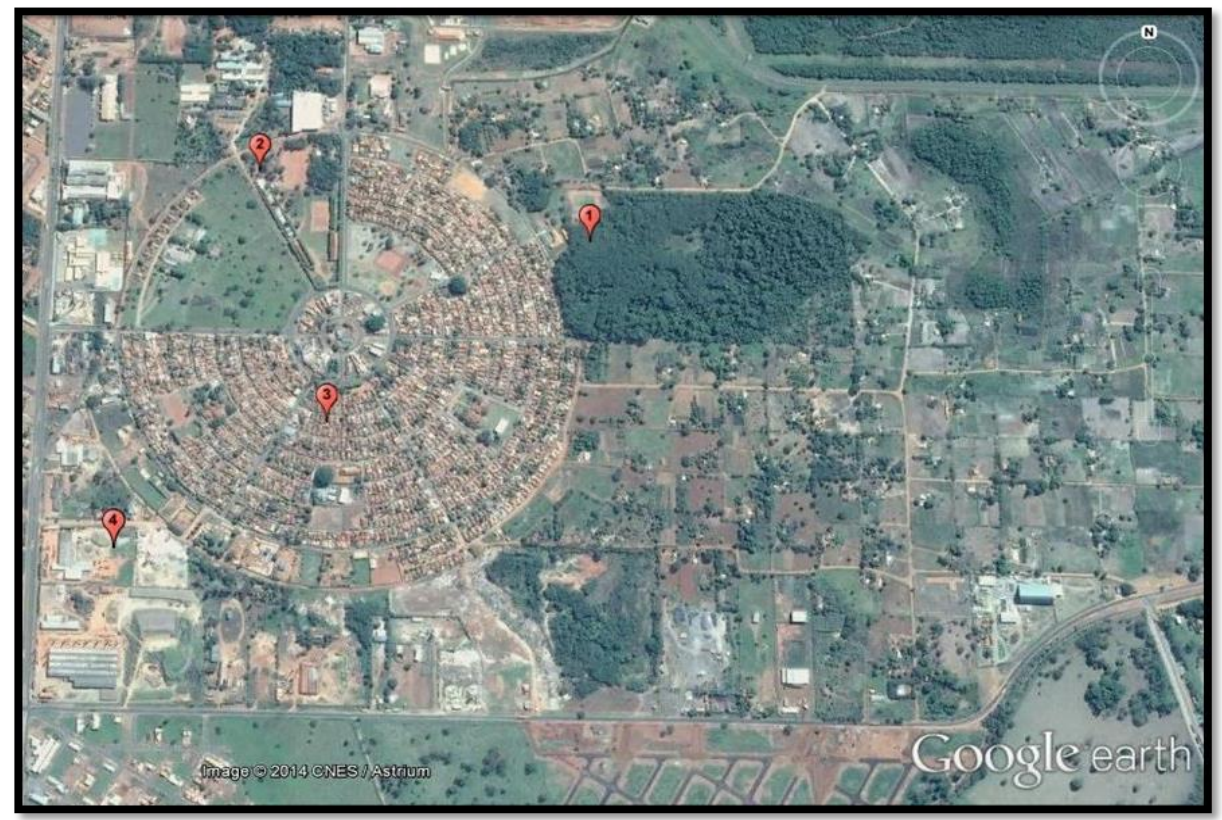

Fonte: Google earth.

Os dados foram descarregados pelo programa Datalogger (Figura 2) instalado em computador de mão que era levando a campo que disponibilizava as informações em forma de gráfico e tabelas para serem analisados e tratados.

Figura 2: sensor Data Logger HT-500 e programa Datalogger para descarregar os dados.

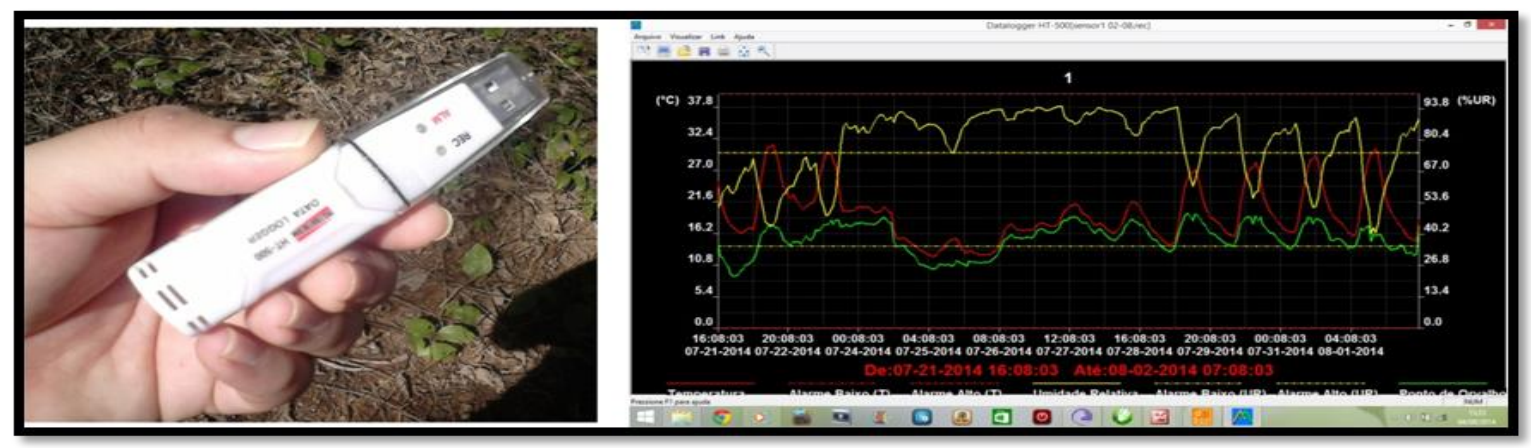

Para o desenvolvimento desta pesquisa foram instalados mini-abrigos meteorológicos (Figura 3), esses abrigos foram replicados de um estudo realizados em Florianópolis/SC (SEVERINO \& MONTEIRO, 1990). Este modelo de abrigo foi copiado, e um pouco alterado daquele montado pelo Professor Jose Roberto Tarifa no Laboratório de Climatologia da USP. 
Figura 3: Mini-abrigo utilizado nas medidas de campo conforme o modelo TAR.

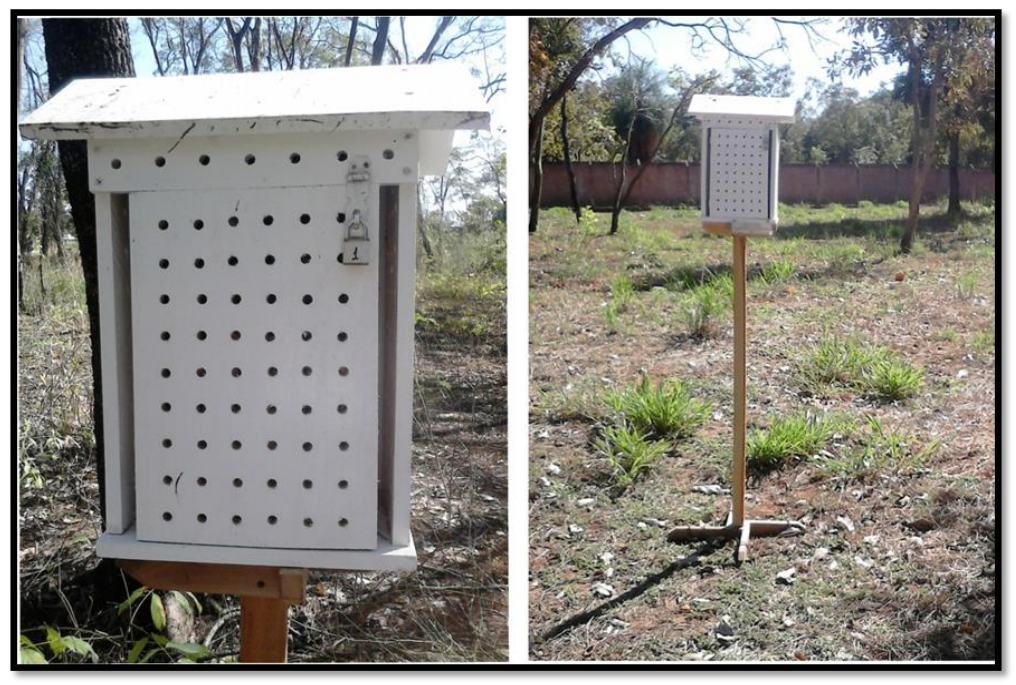

A análise do tempo em escala regional e teve como objetivo identificar e classificar os sistemas atmosféricos que estavam atuando na região durante o período analisado e suas interações com o ambiente estudado. Usaram-se imagens de satélite meteorológico GOES 13 do canal infravermelho disponibilizadas diariamente na internet pelo Centro de Previsão de Tempo e Estudos Climáticos do Instituto Nacional de Pesquisas Espaciais (CPTEC/INPE) e de cartas sinóticas das $00 Z$ e $12 Z$ elaboradas pela Marinha do Brasil, também disponibilizadas na internet.

Os dados de temperatura e de umidade relativa do ar que foram colidos através das informações originais fornecidos pelos sensores foram organizados no programa Microsoft Office Excel 2007 em tabelas e gráficos para uma melhor compreensão das informações climáticas obtidas.

\section{Resultados}

\section{Área de estudo}

O município de Três Lagoas está localizado a leste do Estado de Mato Grosso do Sul, próximo à divisa com o estado de São Paulo está entre as coordenadas

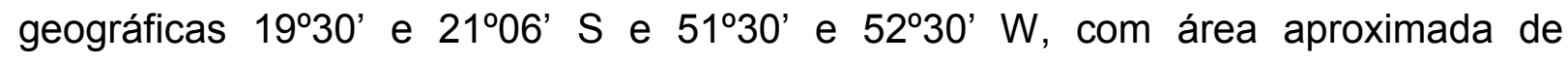
$10.207,045$ km²; $319 \mathrm{~m}$ de altitude em relação ao nível do mar e possui uma população estimada em 109.633 (IBGE, 2013). 
O início da cidade deu-se quando começaram as obras da ferrovia Noroeste do Brasil (NOB). O crescimento urbano motivou a transferência dos equipamentos urbanos para próximo da estação onde atualmente é o centro da cidade de Três Lagoas; ruas e avenidas foram planejadas obedecendo a um plano em xadrez (Figura $5)$.

Figura 5: Localização e uso e ocupação do solo na cidade de Três Lagoas/MS.

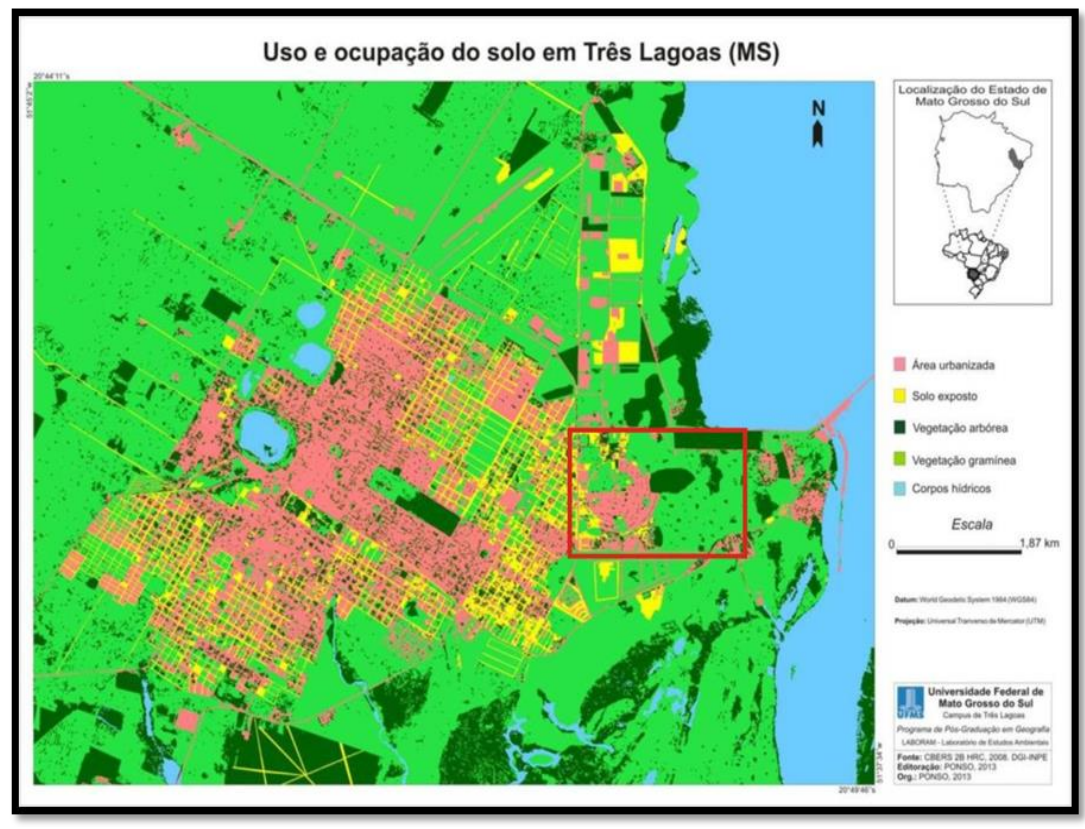

Fonte: PONSO, 2013.

Com a construção da Usina Engenheiro Souza Dias (Jupiá) que começou no início da década de 1960 terminando no ano de 1970, instalada durante o regime militar. O projeto previu a construção de vilas e cidades para alojar os trabalhadores, assim foi construída a Vila Piloto em Três Lagoas/MS.

Atualmente a Vila Piloto e bairro da cidade Três Lagoas foi reconstruída no final da década de 1980 se tornando um bairro popular, o bairro é composto por vários conjuntos habitacionais sendo eles Vila Piloto 1 (1989), Vila Piloto 2 (1989), Vila Piloto 3 (1991), Vila Piloto 4 (2004) e Vila Piloto 5 (2004) de acordo com o Plano Local de Habitação de Interesse Social de Três Lagoas (Prefeitura Municipal de Três Lagoas, 2010). Hoje o bairro conta com escolas, centro formação profissional, unidades de saúde e delegacias (Figura 4). 
Figura 4: Uso e ocupação do solo na Vila Piloto e localização dos pontos de medidas.

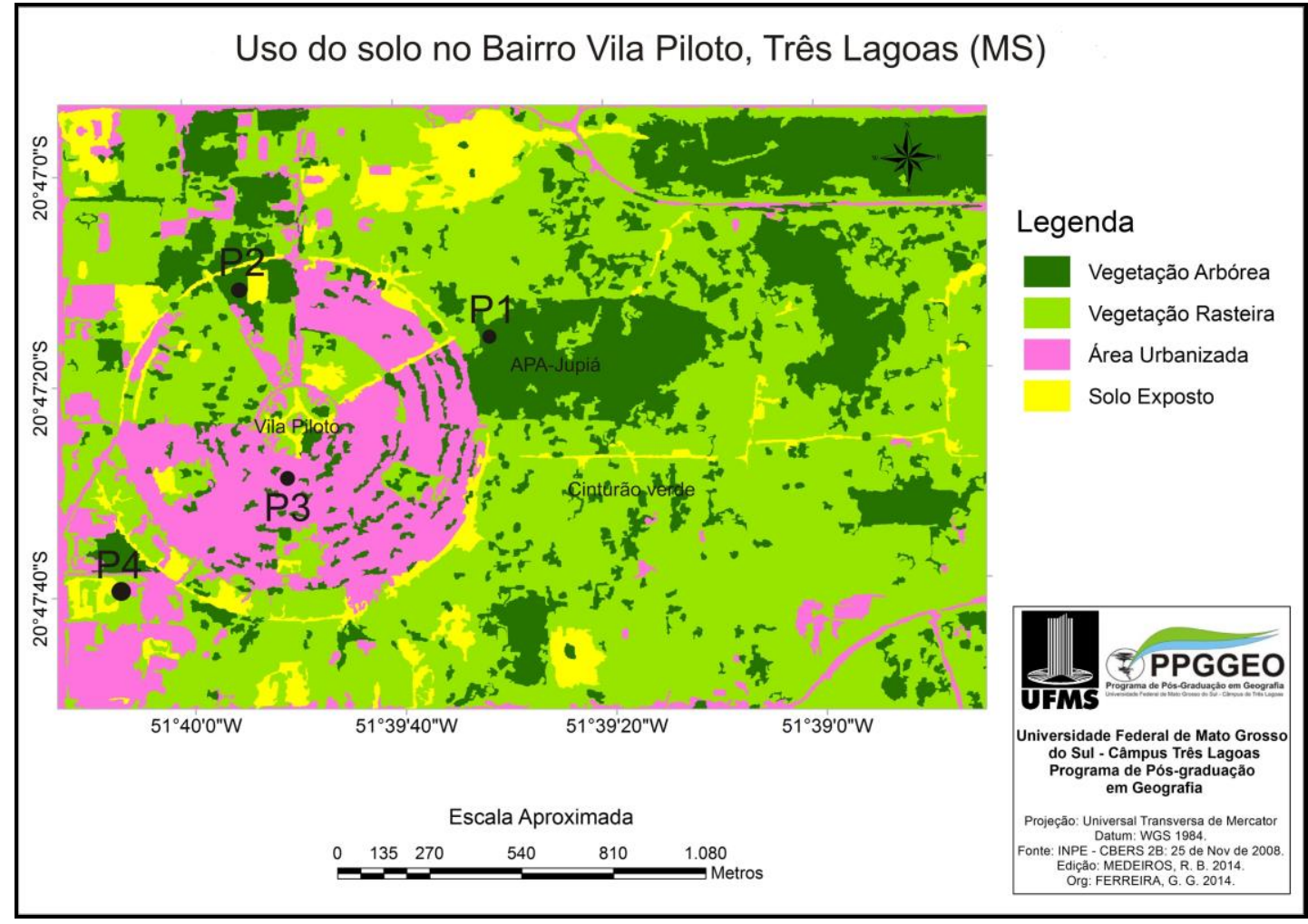

\section{Campo Térmico na Vila Piloto}

Durante o período analisado de 04 a 13 de julho de 2014, no início das medidas de campo o tempo na região de Três lagoas/MS estava sob atuação de uma Massa Tropical Atlântica deixando o céu limpo sem nuvens, mas nos dia 06/07/2014 devido a chegado de sistema frontal modificando as características do tempo deixando o céu coberto de nuvens nos dias 07 e 08/07/2014 o tempo na região ficou sobre domínio de uma Massa Polar Atlântica deixando as temperaturas amenas durante esses dias, no dia 09, 10, 11, 12/07/2014 essa massa Polar começou a se modificar elevando as temperaturas, no dia 13/07/2014 houve a entrada de massa Tropical Atlântica.

No dia 04/07/2014 a partir das 00h as temperaturas se apresentaram mais amenas com exceção do Ponto 3 que mostrou-se com leve aumento na temperatura, nos horários entre $10 \mathrm{~h}$ e $15 \mathrm{~h}$ apresentaram as maiores temperatura do dia devido grande quantidade de radiação solar recebida durante todo o dia, das $15 \mathrm{~h}$ em diante 
as temperaturas começaram a baixar, mas o Ponto 4 mostrou um lentidão para se resfriar (Gráfico 1).

Gráfico 1: Variação da temperatura no dia 04 de julho de 2014 na Vila Piloto.

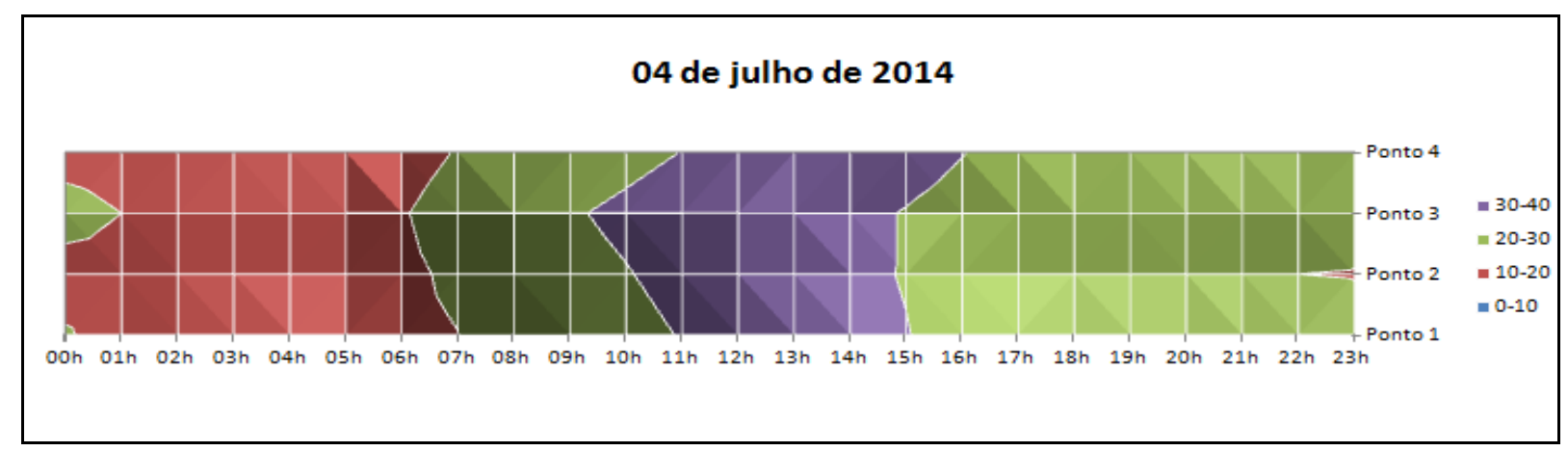

No dia 05/07/2014 apresentou uma maior variação da temperatura em relação ai dia anterior o período da manhã apresentou temperaturas amenas às maiores temperaturas ficaram entre $10 \mathrm{~h}$ e $14 \mathrm{~h}$ com exceção do Ponto 4 que mostrou uma demora para se resfriar. Às $21 \mathrm{~h}$ houve uma queda na temperatura (Gráfico 2).

Gráfico 2: Variação da temperatura no dia 05 de julho de 2014 na Vila Piloto.

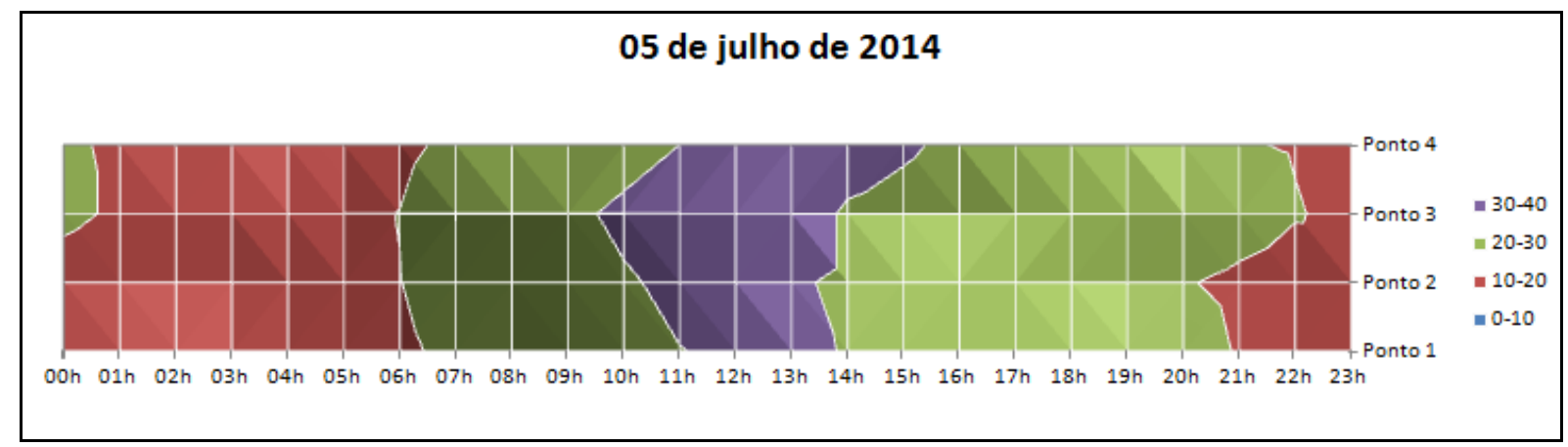

No dia 06/07/2014 as menores temperatura mostraram entre as 00h às 06h em todos os pontos de medidas e as maiores temperaturas apresentaram no inicio da tarde por volta das $11 \mathrm{~h}$ ate às $15 \mathrm{~h}$ quando as temperaturas nos pontos de medidas começaram a baixar deixando-as mais amenas (Gráfico 3). 
Gráfico 3: Variação da temperatura no dia 06 de julho de 2014 na Vila Piloto.

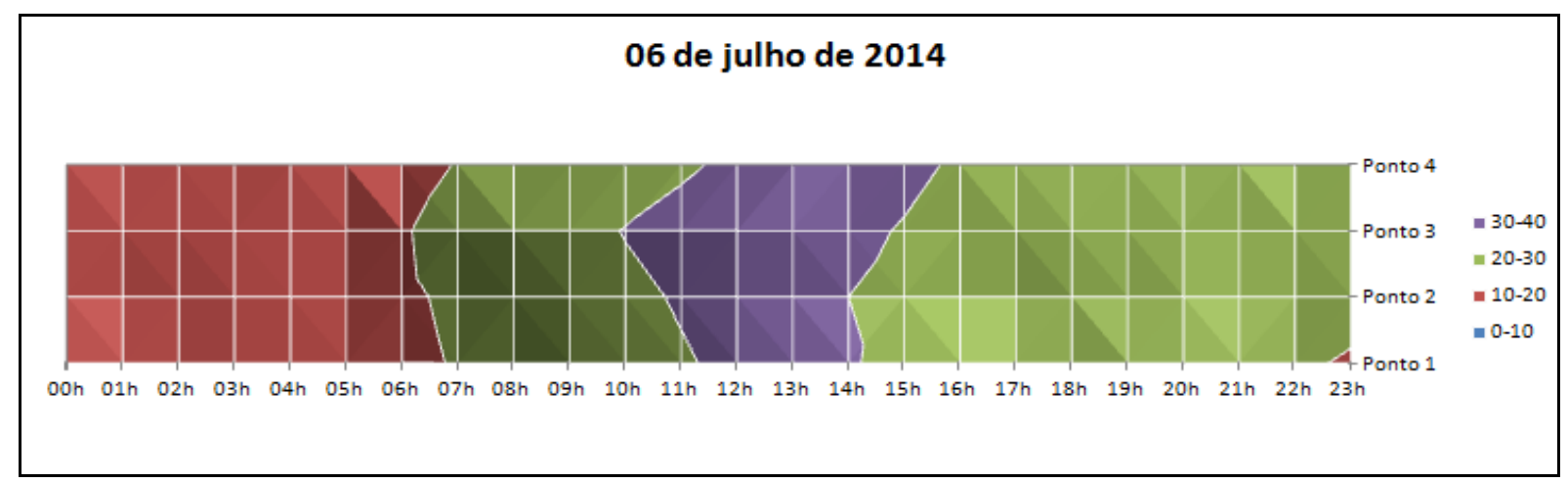

No dia 07/08/2014 devida à entrada de uma frente fria as temperaturas apresentaram se mais baixas em relação aos dias anteriores, sendo que menores estavam no período da madrugada ate o inicio da manha entre $02 \mathrm{~h}$ ate as $08 \mathrm{~h}$ quando começou a esquentar havendo um aumento da temperatura sem mantendo ate o fim do dia (Gráfico 4).

Gráfico 4: Variação da temperatura no dia 07 de julho de 2014 na Vila Piloto.

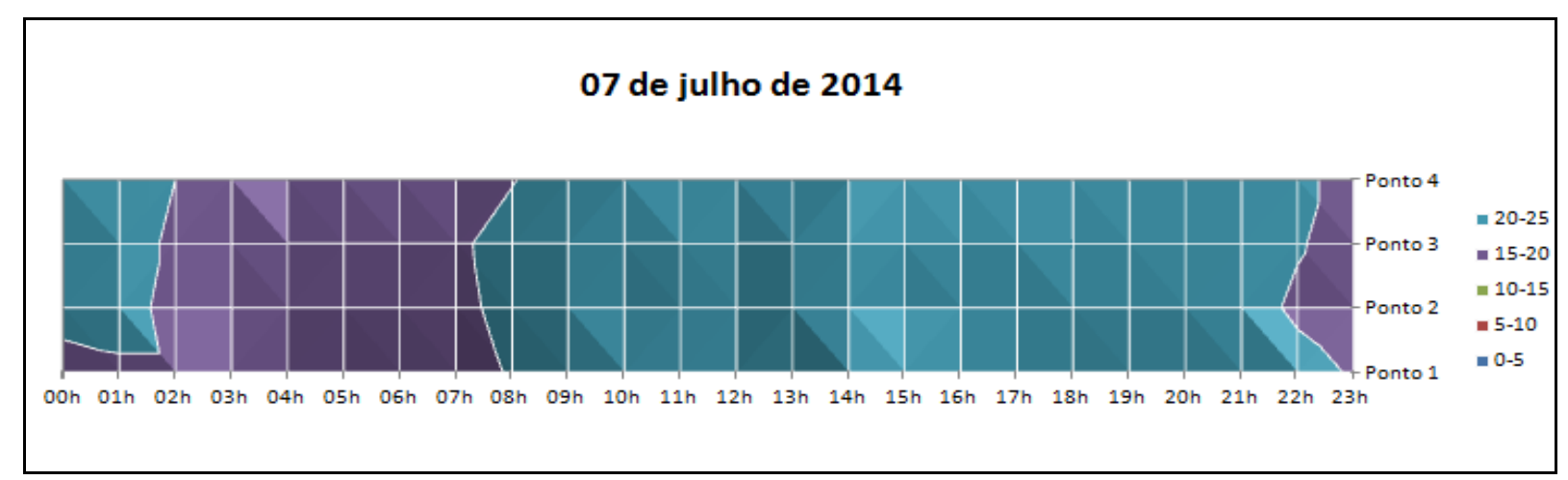

No dia 08/07/2014 as menores temperaturas estavam entre $00 \mathrm{~h}$ e às $08 \mathrm{~h}$ e depois no fim do dia entre às $19 \mathrm{~h}$ e $23 \mathrm{~h}$, as maiores temperaturas do dia ficaram entre $09 \mathrm{~h} 19 \mathrm{~h}$. Em relação ao dia anterior as temperaturas foram mais baixas devido a intensificação da frente fria (Gráfico 5). 
Gráfico 5: Variação da temperatura no dia 08 de julho de 2014 na Vila Piloto.

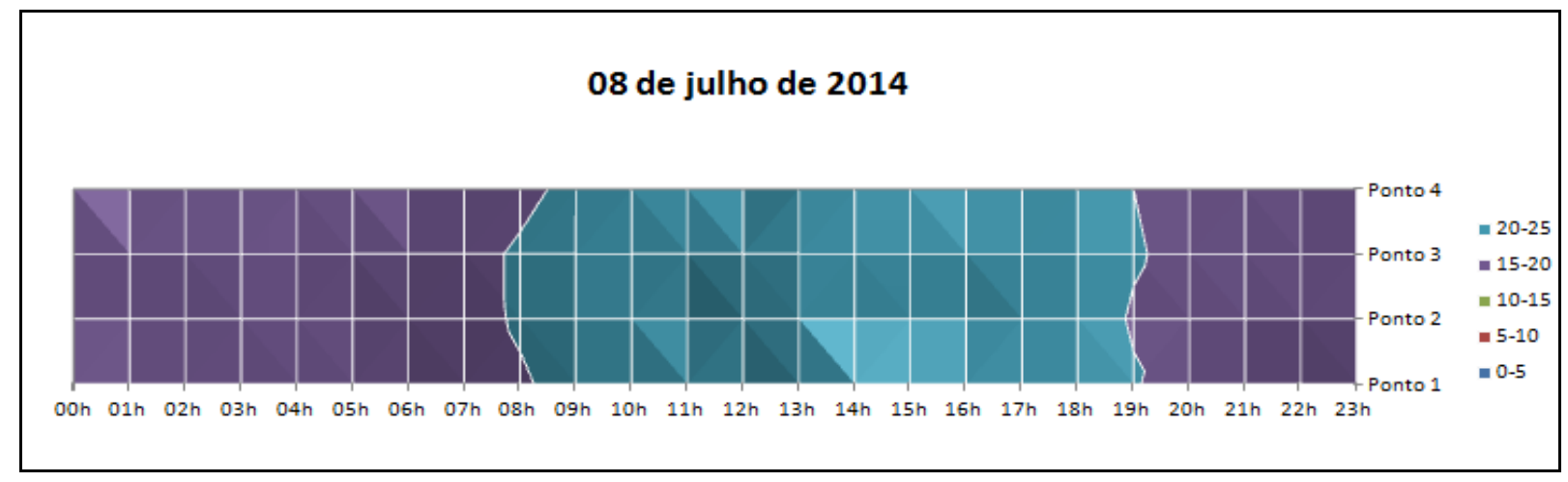

No dia 09/07/2014 as temperatura horárias em relação o dia anterior aumentaram significativamente, sendo que as maiores temperaturas ficaram entre as $08 \mathrm{~h}$ e às $16 \mathrm{~h}$ e as temperaturas menores apresentaram-se em dois períodos do dia de madrugada ate o inicio da manha das $00 \mathrm{~h}$ ate às $07 \mathrm{~h}$ e no fim da tarde até o fim do dia das 16 h até às 23h (Gráfico 6).

Gráfico 6: Variação da temperatura no dia 09 de julho de 2014 na Vila Piloto.

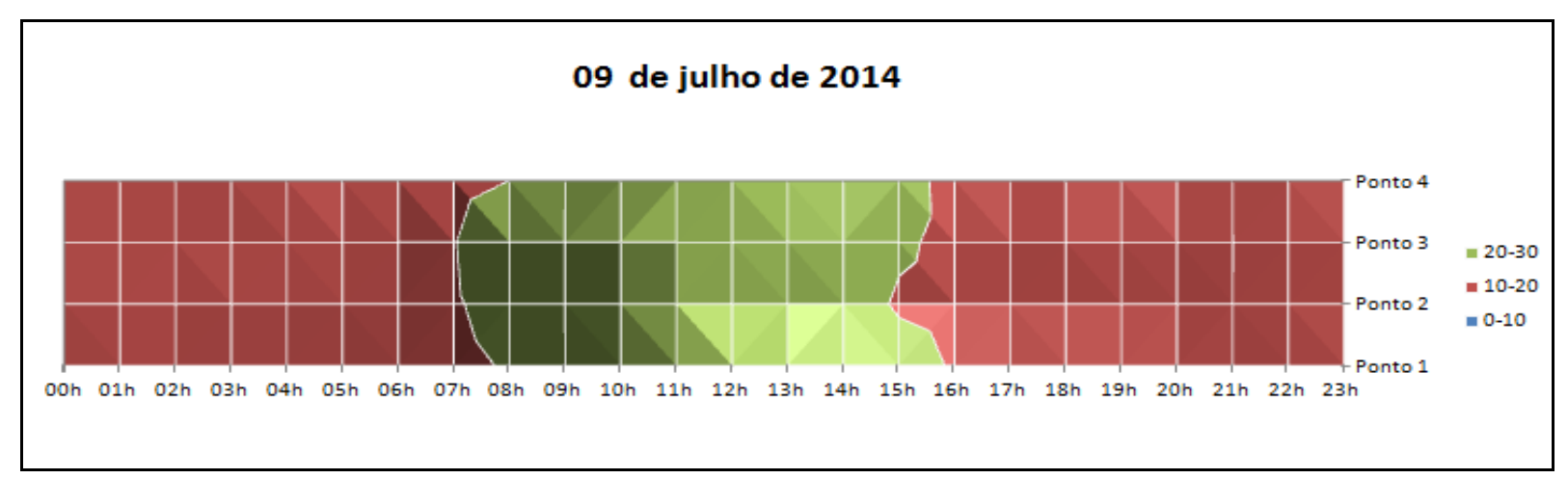

No dia 10/07/2014 as temperatura apresentaram as mais baixas dos dias estudos, sendo que não ultrapassaram os $25^{\circ} \mathrm{C}$ entre as $12 \mathrm{~h}$ e $15 \mathrm{~h}$ e as menores temperaturas ficaram durante o período da manha e da noite (Gráfico 7). 
Gráfico 7: Variação da temperatura no dia 10 de julho de 2014 na Vila Piloto.

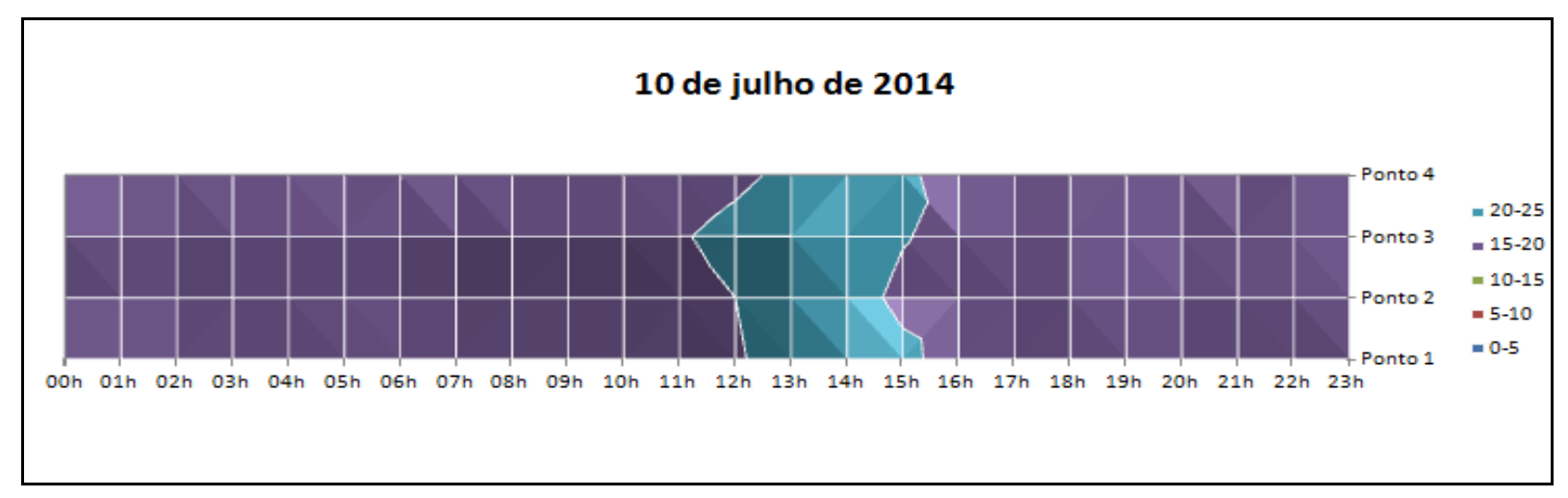

No dia 11/07/2014 tiveram um aumento significativo principalmente nos horários da manhã e tarde entre $08 \mathrm{~h}$ ate às $18 \mathrm{~h}$ e as menores temperaturas apresentaram-se nos horários com pouca ou sem radiação solar no período da madrugada e a noite (Gráfico 8).

Gráfico 8: Variação da temperatura no dia 11 de julho de 2014 na Vila Piloto.

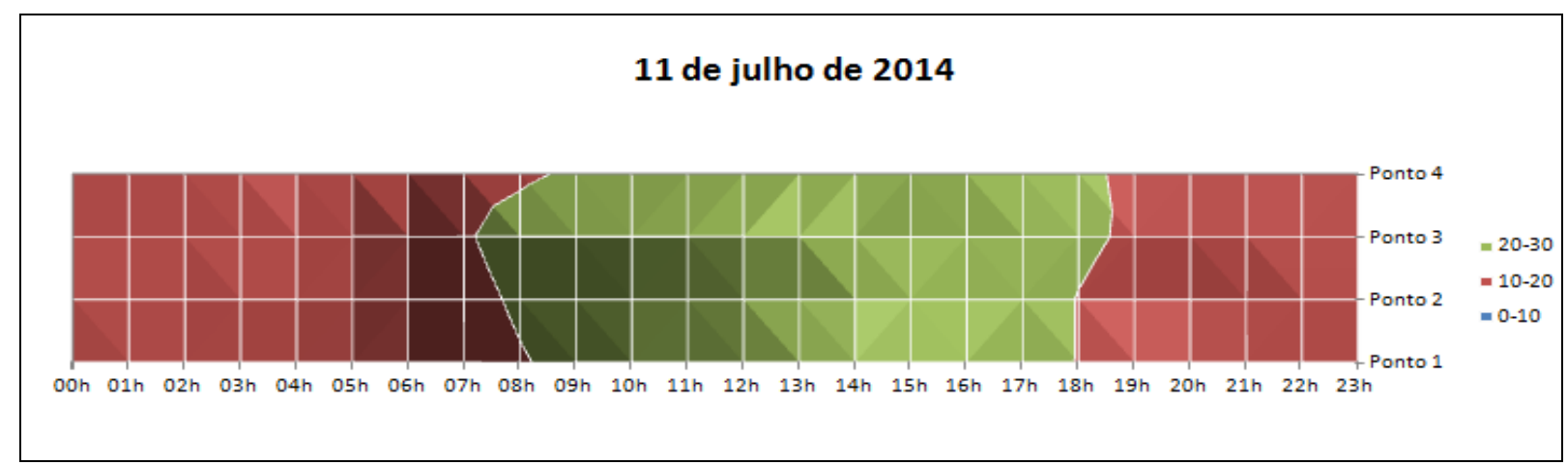

No dia 12/07/2014 às $12 \mathrm{~h}$ o Ponto 3 apresentou um aumento na temperatura em relação aos demais pontos de medidas que apresentação temperaturas abaixo dos $30^{\circ} \mathrm{C}$ as menores temperaturas ficaram durante a madrugada e a noite (Gráfico 9). 
Gráfico 9: Variação da temperatura no dia 12 de julho de 2014 na Vila Piloto.

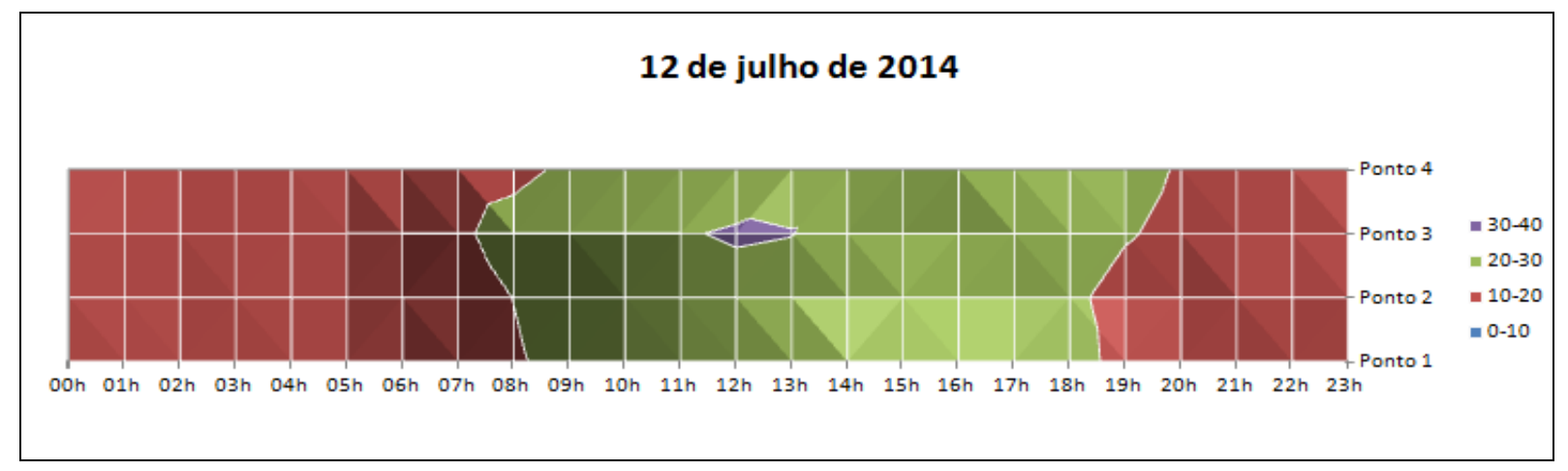

No dia 13/07/2014 as maiores temperaturas ficaram entre $11 \mathrm{~h}$ e $13 \mathrm{~h}$ principalmente nos pontos 3 e 4 que apresentaram temperaturas mais elevadas os demais pontos nesses horários mostraram temperaturas amenas, as menores temperaturas conforme os dias anteriores ficaram nos períodos de pouca e sem radiação solar na madrugada e a noite (Gráfico 10).

Gráfico 10: Variação da temperatura no dia 13 de julho de 2014 na Vila Piloto.

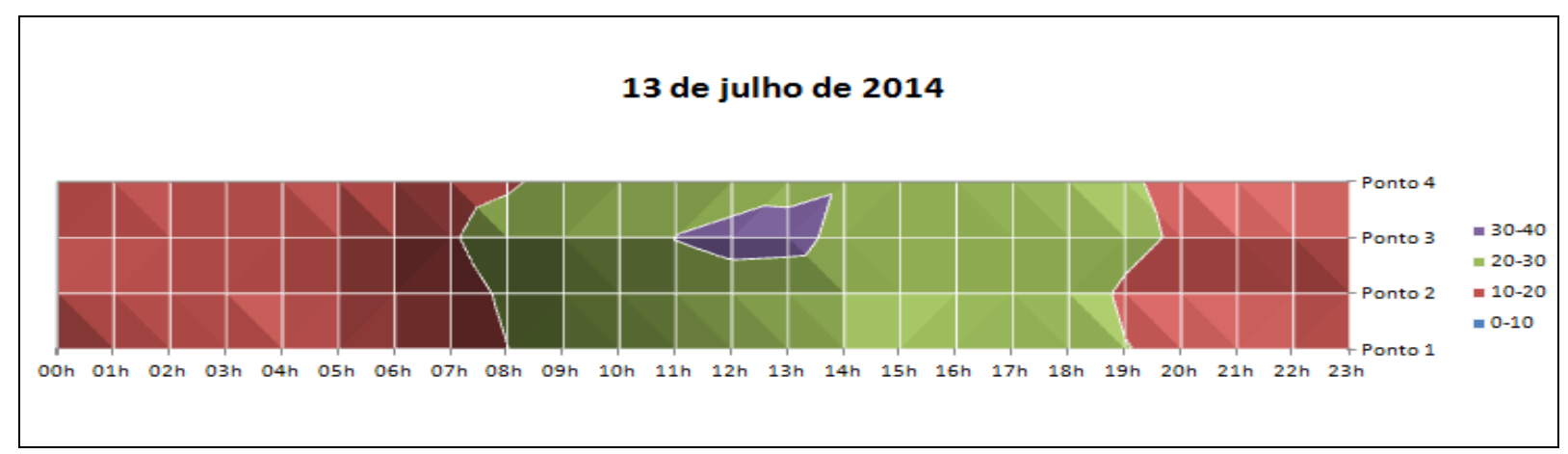

O Ponto 1 durante o período de medidas apresentou temperaturas mais baixas em relação aos outros pontos, principalmente nos horários de pouca radiação, devido também ao local ser uma área de mata fechada e sombreada durante o dia claro.

O Ponto 2 também apresentou temperaturas mais elevadas do que o Ponto 1, mas mais baixas em relação aos pontos 3 e 4 , durante os horários de pouca 
radiação as temperaturas se mantiveram mais amenas, mas durante os horários de muita radiação houve um aumento significativo da temperatura do ar no local.

O Ponto 3 por ser uma áreas de ocupação densa dentro da Vila Piloto, onde as ruas são estreitas e com pouca ventilação e grande circulação de veículos e pessoas, as casas são bem próximas umas das outras e sem presença de vegetação no local, as temperaturas apresentaram-se mais elevadas do que os outros pontos durante os horários de grande incidência de radiação solar.

O Ponto 4 que está dentro de uma áreas de atividade industrial do cerâmica de ocupação esparsa sem a arborização não tendo sombra em nenhum período do dia e grande circulação de veículos de grande porte , o Ponto 4 assim como o Ponto 3 também apresentou temperaturas elevadas nos horárias de intensa radiação.

Durante os dias de medidas houve uma variação dos tipos de tempo atuando na região que influenciaram de forma significava no campo térmico da Vila Piloto o Ponto 1 e o Ponto 2 foram os que apresentaram temperaturas mais baixas, mostrando assim a importância da presença da vegetação para sensação de conforto térmico. Os pontos 3 e 4 diferente dos pontos 1 e 2 mostraram temperaturas mais elevadas devida a grande atividade antrópica nos locais desses pontos.

\section{CONCLUSÃO}

Para a presente pesquisa que ainda esta em andamento os dados mostraram até a presente fase do trabalho que falta de arborização acaba levando a um aumento significativo na temperatura do ar, principalmente nos horários de intensa radiação solar podendo afetar diretamente na sensação de conforto térmico dos seres vivos e falha de planejamento urbano ligado à falta de políticas públicas ligadas a questão da vegetação urbana.

\section{REFERÊNCIAS}

MONTEIRO, C.A.deF.; MENDONÇA, F. (org.), Clima Urbano. São Paulo: Contexto, 2003.

MONTEIRO, C.A.de F. - Teoria e Clima Urbano. São Paulo: IGEOG/USP, 1976. 
MONTEIRO, C. A. Adentrar a cidade para tomar-Ihe a temperatura. Revista Geosul. Florianópolis-SC: Editora da UFSC, 1990. n. 9, Ano v, Primeiro Semestre, p. 61-80, 1990.

PAZERA, E. J. A Ilha de Calor da Cidade: Fatores e Atributos. Bol. Geogr. (RJ), 34 (249): $51-57$ abr/jun, 1976.

PONSO, A. G., Estudo do Campo Térmico da Cidade de Três Lagoas (MS): uma análise sazonal com episódios representativos, 2014, Dissertação (Mestrado - UFMS), Três Lagoas, 2014.

PONSO, A. G.; FERREIRA, C. C.; Uso de Geotecnologias Para a Elaboração de um Mapa temático de Uso do Solo Para Estudos de Clima Urbano de Três Lagoas (MS). In: X ANANPEGE, Anais... Campinas, 2013.

VIANNA, M. P., O desmonte e a conversão dos núcleos residenciais operários construídos pela CESP. In: Revista de Pesquisa em Arquitetura e Urbanismo. São Carlos, 2006.

VIANNA, M. P., Da Edificação ao Traçado Urbano: A Experiência de Planejamento Regional Integrado da CESP. 2012, Tese (Doutorado - Arquitetura e Urbanismo) Universidade de São Paulo, São Carlos, 2012. 